\title{
Investigation of the effects of a fan-shaped Mewis duct before a propeller on propulsion performance
}

\author{
Xin Chang ${ }^{1}$. Shuai Sun ${ }^{1}$ [D $\cdot$ Yuchang Zhi $^{1} \cdot$ Yuming Yuan $^{1}$
}

Received: 20 June 2017 / Accepted: 28 January 2018 / Published online: 7 February 2018

(c) The Author(s) 2018. This article is an open access publication

\begin{abstract}
To define the guidelines for the design of a Mewis duct for a small bulk cargo ship, a numerical study was carried out to investigate the effects of a fan-shaped Mewis duct on propeller performance of a 38,000 $t$ bulk cargo ship with a three-blade propeller. Calculations were performed using the STAR-CCM+ software based on the solution of the Reynolds averaged Navier-Stokes (RANS) equation. Computations were carried out for a wide range of locations from $0.11 D$ to $0.21 D$ upstream from the propeller disc, a radius of trailing edge from $0.65 R$ to $1.05 R$, and angle of attack of the inner fins, where from $0^{\circ}$ to $10^{\circ}$ of the fan-shaped Mewis duct, where $D$ is the diameter of the propeller and $R$ is the radius of the propeller. With the installation of the duct, the axial mean wake fraction on the propeller disc decreased, while the tangential mean wake fraction increased significantly. As the installation position was far away from the propeller, the axial mean wake fraction varied in a wave pattern, while the tangential mean wake fraction increased. With the increase of the radius and the angle of attack of the inner fins of the duct, the axial mean wake fraction first decreased and then increased, while the tangential mean wake fraction increased gradually. Correspondingly, the propeller force coefficients and efficiencies with the duct were all more than those without the duct and changed with the variations of the duct parameters. When the propeller and duct were taken as a propulsion system, the efficiency of the system was less than that of only the propeller. At the same time, with variations of the location, radius, and angle of attack of the inner fins of the duct, the efficiency of the system first increased and then decreased gradually, which indicates that there was an optimum design value for all of the duct parameters. Moreover, only when the design of these duct parameters are reasonable can energy savings be achieved; otherwise, the opposite effect is produced. Eventually, with the installation of the fan-shaped Mewis duct, the wake harmonic degree on the propeller disc can be significantly improved.
\end{abstract}

Keywords Fan-shaped Mewis duct $\cdot$ Energy saving $\cdot$ Propeller $\cdot$ Wake fraction $\cdot$ Force coefficient

\section{Introduction}

At present, marine propellers are still the most commonly used propulsion device. Energy savings and low-carbonemission output are currently the two inevitable trends in the shipbuilding industry. Meanwhile, the aims of ship energy savings and emission reductions have promoted the rapid development of the research in energy-saving devices (ESDs), which can be installed before the propeller, at the propeller station, and after the propeller [1]. ESDs can reduce energy loss by producing additional thrust, improving

Shuai Sun

sunshuaidoc@163.com

1 College of Shipbuilding Engineering, Harbin Engineering University, Harbin, People's Republic of China the inflow on the propeller plane, or recovering the rotation energy of the tail of the propeller.

The propeller works in the wake field at the stern of the ship. Due to the influence of the wake, the actual efficiency of the propeller is different from that of being in open water. A high wake zone is usually found in the upper half of the propeller disc which results in the decrease of propulsion efficiency, the deterioration of cavitation performance, and the increase of exciting force levels [2]. Many additional devices have been designed to improve the hydrodynamic performance and to reduce cavitation and noise. A lot of research has been done on the working mechanisms and effectiveness of these devices [3-18].

For the equalization of the propeller inflow and improvement of the propulsion efficiency, one of the energy-saving devices used widely in ships is the pre-duct such as the wake 
equalizing duct (WED) and the Mewis duct, while Schneekluth [19] introduced the WED first. In fact, the WED was first fitted onto a large ship in March 1984, while model tests were carried out beforehand. WEDs aim to improve the overall propulsion efficiency of the ship by improving the inflow of the propellers.

To explore the special features of rudder balls and WEDs, Dayuan [20] carried out model tank tests for the 65,655 DWT bulk carriers and satisfactory results were obtained. He believed that the simultaneous use of rudder balls and WEDs was a practical solution for energy saving in fully laden vessels.

To investigate the scale effects of the ducts, Friesch and Johannsen [21] performed resistance and self-propulsion tests on a large single screw tanker ship with and without a WED in the large hydrodynamics and cavitation tunnel of the Hamburg Ship Model Basin (HYKAT). They reported that the effectiveness of the energy savings of a WED would decrease when increasing the Reynolds number further and disappear totally at full scale. They thought that the measurements should be understood as a possible explanation for the discrepancy between predicted gain and reality.

To study the effect of a partial WED on the powering characteristics of the subject vessel, Korkut [22] carried out resistance, self-propulsion, and flow visualization measurements for a river going general cargo ship. To improve the stern flow characteristics of the original hull form, the stern form of the vessel was optimized and two different hull forms were generated. He found that a partial WED with optimized stern forms would result in less resistance and effective power requirement than those of the original hull form, which indicates that the duct can improve the powering characteristics.

Çelik [23] numerically investigated the effect of a WED on the propulsion performance of a chemical tanker. The propulsion characteristics, path lines over the after body, and viscous resistance forces were analyzed for six WED cases combined with the ship and propeller at various ship speeds. He thought that the ship's viscous resistance forces and propeller propulsive characteristics were not changed with ducts, but the WEDs generated a positive thrust, which resulted in a maximum increase of the propulsive efficiency by $9.7 \%$. He concluded that a well-designed WED can improve the propulsion characteristics of a ship considerably, while a poorly designed WED can cause negative effects.

Mewis [24-26] developed the Mewis duct for smaller container ships and bulk carriers by combining a WED with pre-swirl fins. Studies show that a Mewis duct can lead to an energy savings between 7 and $9 \%$.

Hans-Jürgen Heinke [27] carried out calculations by computational fluid dynamic (CFD) in model and full scale for a typical container ship with a WED to investigate the scale effect on the flow around the WED and on the inflow to the propeller. The calculation results showed that the change of the propulsion coefficients thrust deduction fraction, wake fraction, and hull efficiency of the ships with WEDs can be predicted with reasonable accuracy using the ITTC 1978 propulsion prognosis method. The use of a WED leads to a reduction of the propeller induced pressure fluctuations in the first and second harmonic orders.

Carlton [1] pointed out that a WED can help to establish a more uniform inflow into the propeller to reduce the amount of separation over the after body of the vessel by accelerating the flow in the upper region of the propeller disc, and by attempting to minimize the tangential velocity components in the wake field.

Feizi Chekab and Ghadimi [28] investigated noise reduction methods for submerged marine propellers by modifying the wake inflow with a WED and a Mewis duct. He reported that the efficiency of the propulsion system can be improved, and the propeller's cavitation and vibrations could be reduced with the modification of wake inflow.

Go and Yoon [29] aimed at providing the general information for the duct design regardless of the ship type, and considered a wide range of duct diameters and angles of the attack. They numerically investigated the effects of duct diameters and angle of attack on the hydrodynamic forces and efficiency of a marine propeller by carefully analyzing the related flow fields. He imposed a uniform inflow condition without considering the type of ship to investigate the net effect of a duct on propeller performance. He found that when the drag of the duct excluded the thrust coefficient, torque coefficient, and propeller efficiency of the propeller all augments with the increasing angle of attack of the duct and all coefficients of the propeller with the duct were larger than those of the propeller without the duct. In addition, it was found that a duct with a high angle of attack provides faster inflow into the propeller than in the case without a duct.

Other researchers have also investigated the effects of WEDs on propulsive performance including [30-35].

According to our review of the references, most researchers that have studied the working mechanisms or the effects of a pre-duct believe that a pre-duct can help improve the propulsion performance of a vessel. However, the effect of energy savings of a pre-duct usually depends on the hull form of the stern. For a Mewis duct, in addition to the hull form, its several characteristic parameters have great influence on its performance including the installation position, radius, angle of attack of the inner fins, profile of the inner fins and outer duct, and so on. To achieve better energy-saving effects, these parameters should be optimized. However, in the past, the design of a pre-duct was largely a matter of experience based on model tests, because it is difficult to find guidelines for the design of these parameters of the duct 
independent of hull form. Thus, the designers had to test and verify their designs in actual use, which often makes the applications of pre-ducts questionable.

In the present study, for a small bulk cargo ship, the effects of a fan-shaped Mewis duct with different characteristic parameters were investigated to find the effect it had on the propulsion performance of the propeller. The fan-shaped Mewis duct was developed by the Shanghai Merchant Ship Design and Research Institute. The choice of characteristic parameters of a Mewis duct depends on the ship type, and it is futile to find guidelines applicable to all ship types. Therefore, the conclusions from the present study are only applicable to small bulk cargo ships. Our research mainly focused on the relationship between propulsion performance of propeller and characteristic parameters of the Mewis duct. If this relationship is known, the optimized design of the Mewis duct can be created more efficiently for a small bulk cargo ship.

For a 38,000-t bulk cargo ship, a wide range of duct locations, duct radius, and angle of attack of the inner fins were considered and the effects of these parameters on the hydrodynamic forces, efficiency, and wake harmonic degree were numerically investigated by carefully analyzing the wake fractions of the related flow fields. The relationship between the propulsion performance of propeller and the characteristic parameters of the Mewis duct was needed, and it is believed that the results will be helpful to the design of the Mewis duct for small bulk cargo ships.

\section{Numerical model}

\subsection{Governing equations}

The three-dimensional incompressible steady-state flow problem is governed by continuity and the Navier-Stokes equations [29], which can be described as

$\frac{\partial u_{i}}{\partial x_{i}}=0$,

$$
\begin{aligned}
\frac{\partial}{\partial t}\left(\rho u_{i}\right)+\frac{\partial}{\partial x_{j}}\left(\rho u_{i} u_{j}\right)= & -\frac{\partial p}{\partial x_{i}}+\frac{\partial}{\partial x_{j}}\left[\mu\left(\frac{\partial u_{i}}{\partial x_{j}}+\frac{\partial u_{j}}{\partial x_{i}}\right)\right] \\
& +\frac{\partial}{\partial x_{j}}\left(-\rho \overline{u_{i}^{\prime} u_{j}^{\prime}}\right),
\end{aligned}
$$

where $x_{i}$ are Cartesian coordinates, $u_{i}$ are the velocity components, $\rho$ is the water density, $p$ is the pressure, $\mu$ is the dynamic viscosity, and $-\rho \overline{u_{i}^{\prime} u_{j}^{\prime}}$ is the Reynolds stress term closed by the SST $k-\omega$ turbulence model with the standard wall function. This turbulence model was recommended by the Specialist Committee on CFD in Marine Hydrodynamics of 27th ITTC [36]. These equations are discretized into algebraic equations based on the finite-volume method. The commercial code STAR-CCM+ was used for solving the algebraic equations. The convection term of the momentum equation was discretized by QUICK, while the diffusion term was discretized by the second-order central difference scheme. The SIMPLEC algorithm was used for the velocity-pressure coupling and the moving reference frame (MRF) scheme was adopted for the rotation of the propeller. A convergence criterion of $10^{-6}$ was used, and further details can be found in the STAR CCM+ manuals [37].

\subsection{Boundary conditions}

A fixed Cartesian coordinate system with respect to the ship was used. As shown in Fig. 1, the computation domain was defined by the boundaries as follows. The inflow boundary, with a $1.5 L_{\mathrm{WL}}$ upstream distance from the ship's midsection, was set as the velocity-inlet boundary condition, where $L_{\mathrm{WL}}$ is the length of water line of the ship. The outflow boundary, with a $3.5 L_{\mathrm{WL}}$ downstream distance from the ship's midsection, was set as the undisturbed pressure-outlet boundary condition. The outer boundary, with a $1.5 L_{\mathrm{WL}}$ distance from the central axis of the model, was set as the undisturbed velocity boundary condition. The hull surface and duct were set as no-slip boundary conditions. The propeller blades were set as rotating non-slip surfaces.

\subsection{Geometry}

A fan-shaped Mewis duct installed on a 38,000-t bulk cargo ship with a three-blade propeller was studied. The ship, propeller, and duct were all designed by the Shanghai Merchant Ship Design and Research Institute. Marine Design and Research Institute of China has made detailed experimental research on the model with the scale factor of 32. The main ship characteristics are summarized

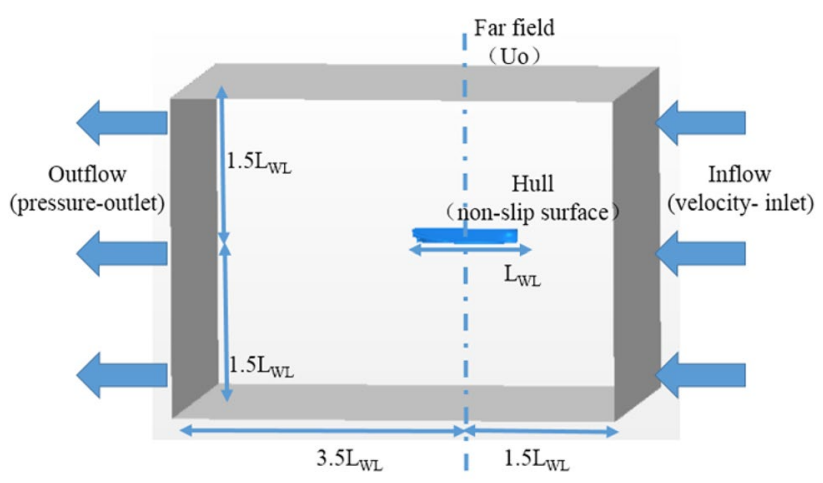

Fig. 1 Schematic of the computational domain and boundary conditions 
Table 1 Principal parameters of the ship

\begin{tabular}{llll}
\hline & Parameter & Unit & Model scale \\
\hline Scale ratio & $\lambda$ & & 32 \\
Length between perpendiculars & $L_{\mathrm{PP}}$ & $\mathrm{m}$ & 5.5313 \\
Length of water line & $L_{\mathrm{WL}}$ & $\mathrm{m}$ & 5.625 \\
Breadth & $B$ & $\mathrm{~m}$ & 1 \\
Draft & $T$ & $\mathrm{~m}$ & 0.2969 \\
Block coefficient & $C_{\mathrm{B}}$ & & 0.786 \\
Displacement volume & $\nabla$ & $\mathrm{m}^{3}$ & 1.3247 \\
Wetted surface area & $S$ & $\mathrm{~m}^{2}$ & 7.3010 \\
Design speed & $U$ & $\mathrm{~m} / \mathrm{s}$ & 1.2731 \\
Froude number & $F n$ & & 0.173 \\
Reynolds number & $R e$ & & $0.704 \cdot 10^{7}$ \\
\hline
\end{tabular}

in Table 1, while the hull's outline is shown in Fig. 2. The principal parameters of the propeller are shown in Table 2.

The propeller with duct is shown in Fig. 3 and the back view of the fan-shaped Mewis duct is shown in Fig. 4.

The fan-shaped Mewis duct consists of an outer duct and four inner guide fins, which was designed using NACA0015. The angle of attack of the outer duct was $15^{\circ}$ and a chord length of $0.28 D$ was used, where $D$ is the diameter of the propeller. The radius of the leading edge was $1.0 R$, where $R$ is the radius of the propeller. The chord length of the inner fins was $0.18 D$. The inner fins were installed on the shaft of the propeller and connected with the outer duct. As shown in Fig. $4, \beta_{1}, \beta_{2}, \beta_{3}$, and $\beta_{4}$ were the intersection angles between the guide fins and the longitudinal centerline of the hub, where $\beta_{1}$ and $\beta_{4}$ were $72^{\circ}, \beta_{2}$ was $28^{\circ}$, and $\beta_{3}$ was $42^{\circ} . \alpha_{1}$, $\alpha_{2}, \alpha_{3}$, and $\alpha_{4}$ were the angle of attack of the inner fins of the duct.

Fig. 2 Lines plan of ship
Table 2 Principal parameters of the propeller

\begin{tabular}{ll}
\hline Parameter & Model scale \\
\hline Scale ratio & 32 \\
Diameter, $D(\mathrm{~m})$ & 0.2 \\
No. of blades & 3 \\
Pitch to diameter ratio & 0.7949 \\
Hub ratio & 0.135 \\
Expanded area ratio & 0.4 \\
Direction of rotation & Right-hand \\
\hline
\end{tabular}

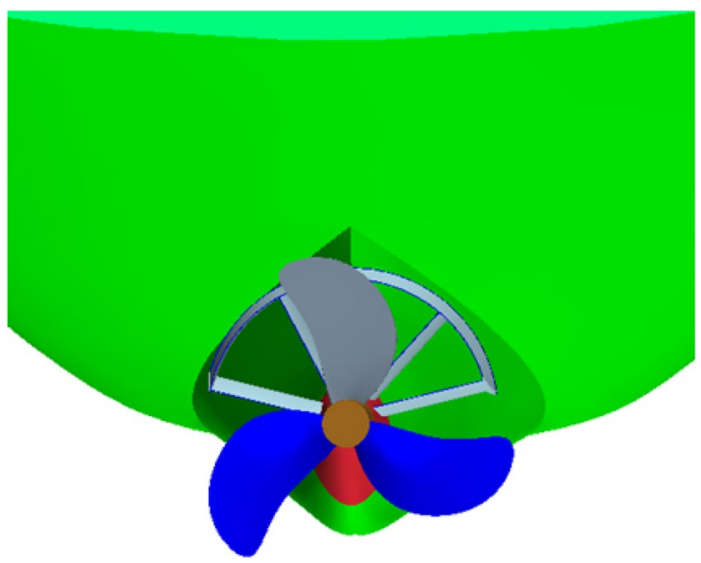

Fig. 3 Propeller with duct at the stern

\subsection{Grid system and validation}

The Cartesian cut cell method was used to generate a computational mesh to cover the global fixed and moving block. The generation of the present grid system follows the same procedure as in Ref. [2].

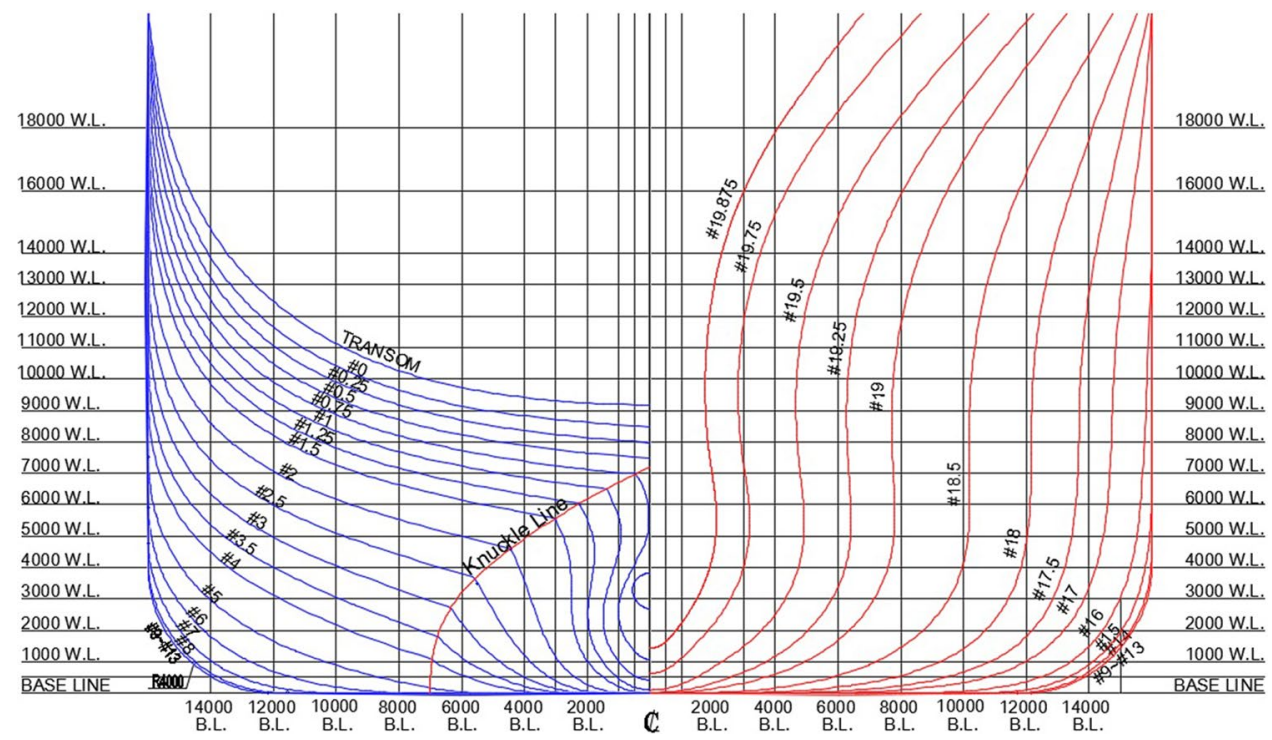




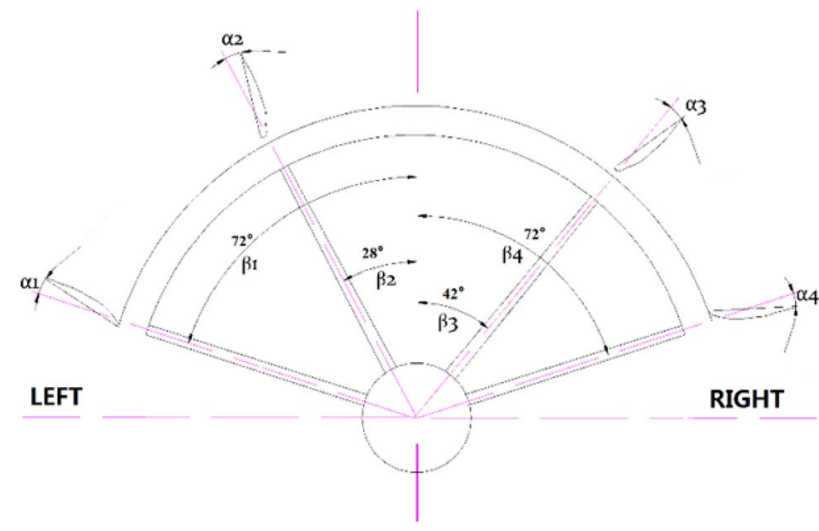

Fig. 4 Back view of the fan-shaped Mewis duct

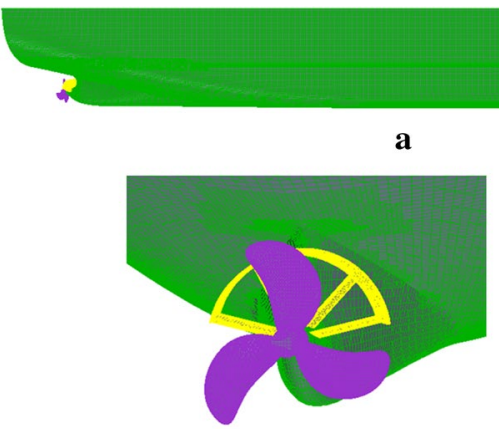

b

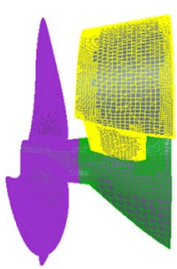

c
Fig. 5 Grid system: a ship, b propeller with duct, and $\mathbf{c}$ side view of propeller with duct

Locally refined and hybrid grids were deployed in the computational domain grid division to guarantee the computational precision and operation speed requirements. In the stern area, including the propellers and duct, unstructured grids were adopted, while the rest used structured grids. The grids are refined to ensure that the aspect ratios of the numerical cells were less than 300 at the middle of the hull and 100 at the bow. The computational grid is shown in Fig. 5.

The grid verification study was performed with three different grids (coarse, medium, and fine) to determine the effect of grid systems on the numerical solution, as
Table 4 Calculation results

\begin{tabular}{lllll}
\hline Grid & $C_{\mathrm{T}}$ & $K_{\mathrm{T}}$ & $K_{\mathrm{Q}}$ & $\eta_{0}(\%)$ \\
\hline Coarse & $4.921 \times 10^{3}$ & 0.142 & 0.0189 & 69.06 \\
Medium & $4.611 \times 10^{3}$ & 0.140 & 0.0184 & 69.98 \\
Fine & $4.572 \times 10^{3}$ & 0.139 & 0.0181 & 70.63 \\
\hline
\end{tabular}

shown in Table 3. The results of verification and validation are listed in Tables 4, 5 and 6, using total resistance coefficient $C_{\mathrm{T}}$, thrust coefficient, $K_{\mathrm{T}}$, torque coefficient, $K_{\mathrm{Q}}$, and propeller efficiency, $\eta_{0}$ [38].

As shown in Table 5, the grid converges ratios $R_{\mathrm{G}}$ of the four parameters is all less than 1 , which suggests that the computational grids exhibit monotonic convergence. A comparison between the calculated results according to different grid systems with the experimental data is listed in Table 6. It can be seen that even if the number of the three sets of grids varies greatly, the errors of $K_{\mathrm{T}}, K_{\mathrm{Q}}$, and $\eta_{0}$ are always controlled within 5\%, which shows that the solutions depend on the grid systems weakly. According to the error of efficiency, $\eta_{0}$, we believe that the medium grid system is the most suitable one to guarantee the calculation accuracy and control computational time.

\section{Results and discussion}

Assuming that the thrust, torque, and rotational speed of the propeller is $T_{0}, Q_{0}$, and $n$, respectively, and the ship's total resistance is $R_{\mathrm{T} 0}$ in the cases without the fan-shaped Mewis duct, the efficiency of the propeller without a duct is

$\eta_{0}=\frac{T_{0} V_{\mathrm{m}}\left(1-W_{\mathrm{a} 0}\right)}{2 \pi n Q_{0}}$

When moving with constant forward speed $V_{\mathrm{m}}$ and rotational speeds $n$, assuming that propeller thrust, propeller torque, and the ship's total resistance are $T, Q$, and $R_{\mathrm{T}}$, respectively, the efficiency of the propeller with a duct is

$\eta_{1}=\frac{T V_{m}\left(1-W_{a}\right)}{2 \pi n Q}$.

With regard to the propeller and the fan-shaped Mewis duct as a propulsion system, the thrust of the system $T_{\mathrm{E}}$ is
Table 3 Grid generation and grid number

\begin{tabular}{llllllll}
\hline Grid & \multicolumn{2}{l}{ Grid number } & & & $y^{+}$ & $\begin{array}{l}\text { Boundary layer } \\
\text { thickness (mm) }\end{array}$ & $\begin{array}{l}\text { Layers number of } \\
\text { boundary layer } \\
\text { grid }\end{array}$ \\
\cline { 2 - 6 } & Ship & Pro. & Duct & Whole & & & \\
\hline Coarse & $1.77 \mathrm{M}$ & $1.23 \mathrm{M}$ & $0.05 \mathrm{M}$ & $3.05 \mathrm{M}$ & 30 & 20 & 8 \\
Medium & $3.03 \mathrm{M}$ & $2.02 \mathrm{M}$ & $0.09 \mathrm{M}$ & $5.14 \mathrm{M}$ & 30 & 20 & 8 \\
Fine & $5.28 \mathrm{M}$ & $3.52 \mathrm{M}$ & $0.16 \mathrm{M}$ & $8.96 \mathrm{M}$ & 30 & 20 & 8 \\
\hline
\end{tabular}


Table 5 Verification study for hydrodynamic forces

\begin{tabular}{lrrlllll}
\hline Parameter & \multicolumn{1}{l}{$\varepsilon_{21}$} & \multicolumn{1}{c}{$\varepsilon_{32}$} & $R_{\mathrm{G}}$ & \multicolumn{1}{c}{$P_{\mathrm{G}}$} & $U_{\mathrm{G}}(\% D)$ & {$[E](\% D)$} & \multicolumn{1}{l}{$D$} \\
\hline$C_{\mathrm{T}}$ & $3.1 \times 10^{-3}$ & $2.5 \times 10^{-3}$ & 0.667 & 3.17 & 0.18 & 2.7 & $4.487 \times 10^{3}$ \\
$K_{\mathrm{T}}$ & $-1.9 \times 10^{-3}$ & $-1.0 \times 10^{-3}$ & 0.532 & 1.8 & 1.0 & 2.3 & 0.138 \\
$K_{\mathrm{Q}}$ & $-5.0 \times 10^{-4}$ & $-3.0 \times 10^{-4}$ & 0.600 & 1.5 & 4.2 & 1.1 & 0.0181 \\
$\eta_{0}$ & $9.3 \times 10^{-3}$ & $6.5 \times 10^{-3}$ & 0.697 & 1.0 & 4.6 & 1.5 & $70.08 \%$ \\
\hline
\end{tabular}

Table 6 Validation study for hydrodynamic forces

\begin{tabular}{llllr}
\hline Grid & Grid number & $K_{T}$ & $K_{Q}$ & $\eta_{0}(\%)$ \\
\hline Coarse & $3.05 \mathrm{M}$ & 0.1420 & 0.0189 & 69.06 \\
Medium & $5.14 \mathrm{M}$ & 0.1401 & 0.0184 & 69.98 \\
Fine & $8.96 \mathrm{M}$ & 0.1391 & 0.0182 & 70.24 \\
EFD & - & 0.1380 & 0.0181 & 70.08 \\
Error 1 & & $2.90 \%$ & $4.42 \%$ & -1.45 \\
Error 2 & & $1.52 \%$ & $1.66 \%$ & -0.13 \\
Error 3 & & $0.79 \%$ & $0.55 \%$ & 0.24 \\
\hline
\end{tabular}

$T_{\mathrm{E}}=T-\left(R_{\mathrm{T}}-R_{\mathrm{T} 0}\right)$.

In addition, the efficiency $\eta_{\mathrm{E}}$ can be expressed as

$\eta_{\mathrm{E}}=\frac{T_{\mathrm{E}} V_{\mathrm{m}}\left(1-W_{\mathrm{a}}\right)}{2 \pi n Q}$.

To predict speed performance, it is necessary to obtain a self-propulsion point of the ship for the given $V_{\mathrm{m}}$. The self-propulsion factors are obtained using the revised ITTC' 78 method [39]. The towing force, $F_{\mathrm{D}}$, that is difference in force between the viscous ship resistance and the propeller thrust $[39,40]$.

The total resistance and propeller hydrodynamic force of the ship model with the design speed of $1.2731 \mathrm{~m} / \mathrm{s}$ were calculated at three different propeller revolution speeds near the self-propulsion point. The results are shown in Table 7, according to which it can be obtained that the propeller revolution speed at the self-propulsion point is $9.11 \mathrm{rps}$. The total resistance, the propeller hydrodynamic force, and the mean wake fraction on the propeller disc are recalculated at the self-propulsion point, as shown in Table 8 .
Under the condition that the design speed was $1.2731 \mathrm{~m} / \mathrm{s}$ and the propeller speed was $9.11 \mathrm{rps}$, the effects of duct location, duct radius of the trailing edge, and the angle of attack of the inner fins on the propulsion performance were analyzed.

\subsection{Duct location}

As shown in Fig. 6, the duct location refers to the longitudinal upstream distance between the trailing edge of the duct and the center of the propeller. The angle of attack of the inner fins was taken as $10^{\circ}$, while the radius was $0.85 R$. The duct locations used were: $0.11 D, 0.135 D, 0.16 D, 0.185 D$, and $0.21 D$.

The axial mean nominal wake fraction and tangential wake fraction on the propeller disc according to the duct location are shown in Fig. 7. It can be seen from Fig. 7a that the axial mean wake fraction decreases when the fan-shaped Mewis duct was installed, which shows that the presence of the duct accelerates the wake flow of the ship. As can be seen from Fig. 7b, when the duct was installed the mean tangential wake fraction increased significantly, and when the duct location increased the mean tangential average wake fraction was augmented. The negative value represents that the flow and the propeller rotation are in opposite directions. The effect of the duct on the propeller performance was caused by the effects of the axial wake and tangential wake simultaneously. The decrease of the axial flow increased the inflow speed of the propeller, while the decrease of the tangential flow increased the relative revolution speed of the propeller. The propeller thrust increased, while the real
Table 7 Propeller performance near the self-propulsion point without duct

\begin{tabular}{llllrll}
\hline & $V_{\mathrm{m}}(\mathrm{m} / \mathrm{s})$ & $N(\mathrm{rps})$ & $R_{\mathrm{T} 0}(\mathrm{~N})$ & $F_{\mathrm{D}}(\mathrm{N})$ & $T_{0}(\mathrm{~N})$ & $Q_{0}(\mathrm{~N} \mathrm{~m})$ \\
\hline Without duct & 1.2731 & 9.33 & 27.31 & 9.24 & 18.07 & 0.4945 \\
& & 9.20 & 26.81 & 9.62 & 17.19 & 0.4740 \\
& & 9.00 & 26.23 & 10.11 & 16.12 & 0.4474 \\
\hline
\end{tabular}

Table 8 Propeller performance at the self-propulsion point without duct

\begin{tabular}{llllllllll}
\hline & $V_{\mathrm{m}}(\mathrm{m} / \mathrm{s})$ & $n$ & $R_{\mathrm{T} 0}(\mathrm{~N})$ & $T_{0}(\mathrm{~N})$ & $\mathrm{Q}_{0}(\mathrm{~N} \mathrm{~m})$ & $W_{\mathrm{a}}$ & $W_{\mathrm{t}}$ & $\eta_{0}(\%)$ & $P_{\mathrm{Dm}}(\mathrm{W})$ \\
\hline Without duct & 1.2731 & 9.11 & 26.49 & 16.61 & 0.46 & 0.1906 & $3.8 \mathrm{e}-5$ & $65.45 \%$ & 26.33 \\
\hline
\end{tabular}




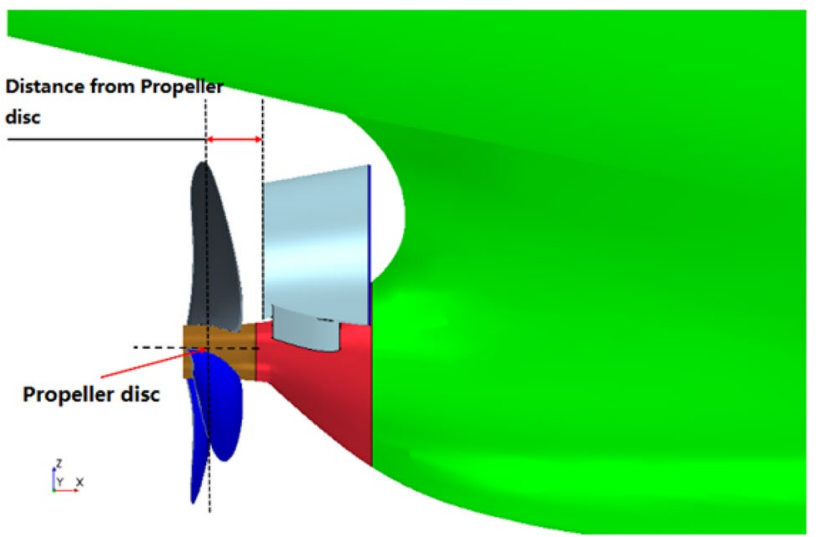

Fig. 6 Duct location

propeller speed did not change, thereby increasing the efficiency of the propeller.

The hydrodynamic performance of the single propeller and the propulsion system consisting of the propeller and duct according to the duct location are plotted in Fig. 8. From Fig. 8, the following conclusions were drawn. The thrust, torque, and efficiency of the propeller with the duct were significantly larger than that without the duct, which means that the duct was favorable to improve the propeller performance. With the installation position of the duct further away from the propeller disc, the thrust, torque, and efficiency of the propeller fluctuated. The thrust and torque had the same changing trend, contrary to the efficiency. This shows that the different installation positions had an impact on the performance of the propeller.

As can be seen from Fig. 8a, when considering the propeller and duct as a propulsion system, the thrust of the system was smaller than that of the single propeller itself. This shows that the propeller efficiency had been improved with the installation of the duct, but additional resistance was also generated. Therefore, the energy-saving effect depends on whether the increase of propeller efficiency can outweigh the adverse effects caused by the additional resistance.

Figure $8 \mathrm{c}$ shows that the efficiency of the propulsion system was significantly lower than that of the single propeller. With the change of the duct location, the efficiency of the propulsion system first increased and then decreased, reaching the maximum at the duct location of $0.16 D$, and only when the duct location was approximately between $0.13 D$ and $0.18 D$ was the energy savings achieved.

As discussed above, the wake flow field varied along with the parameters of the duct. Therefore, a poor design and installation of the duct will cause turbulent changes to the wake flow field, which leads to the increase of noise and exciting forces of the propeller. This is the main reason leading to the vibration of the ship's stern. Therefore, it was necessary to analyze the effect of the duct on the wake harmonic degree on the propeller disc. In this paper, the distribution of the axial velocity of the wake field was analyzed by Fourier transformations to analyze the wake harmonic degree at the radius $0.75 R$ of the propeller disc when the duct parameters changed.

Figure 9 shows the numerical results of the axial wake harmonic degree at the radius $0.75 R$ of the propeller disc according to duct location, where smaller amplitudes indicate a more uniform wake flow on the propeller disc. The first eight terms of the amplitude are listed. The main components of the axial wake amplitude were the first three terms. After installing the duct, the axial wake flow was more uniform than that without the duct, and the first two terms of its amplitudes decreased significantly. The uniformity of the axial wake flow on the propeller disc surface was

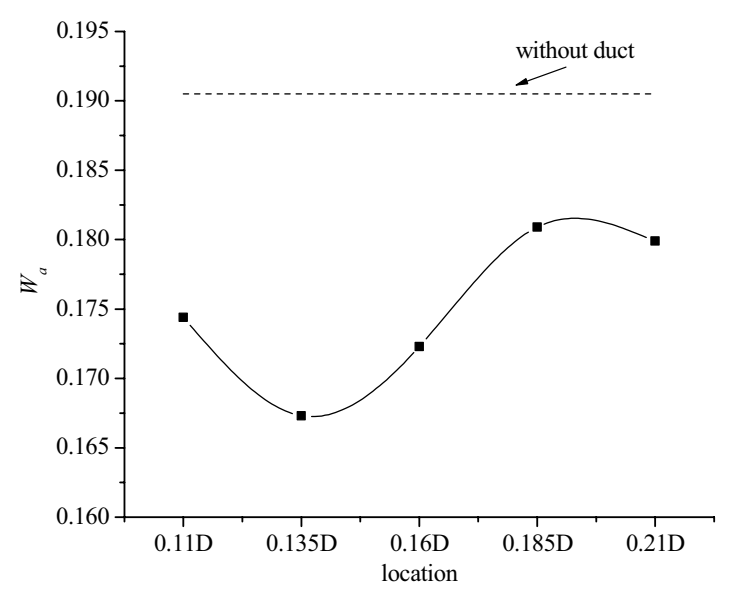

a

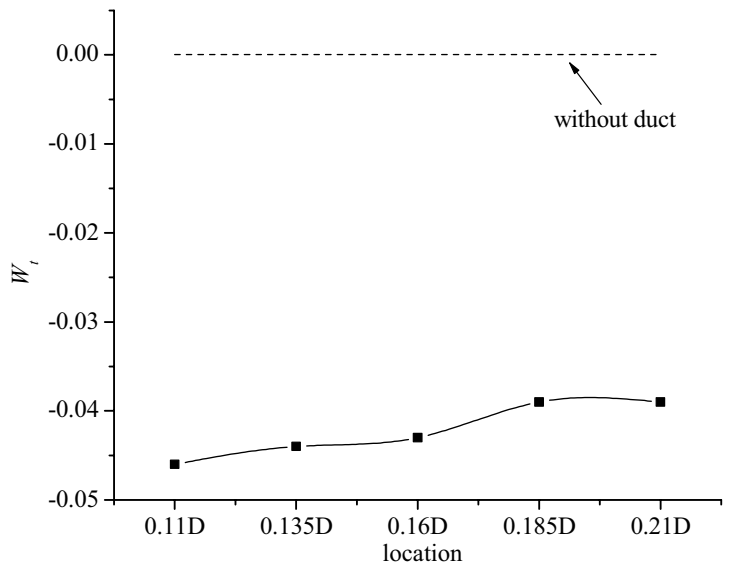

b

Fig. 7 Wake at different duct locations: a axial wake fraction and $\mathbf{b}$ tangential wake fraction 


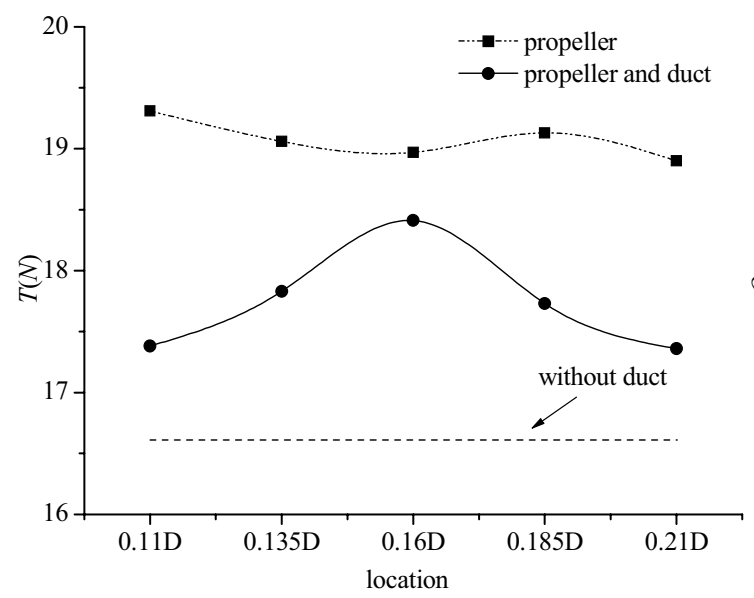

a

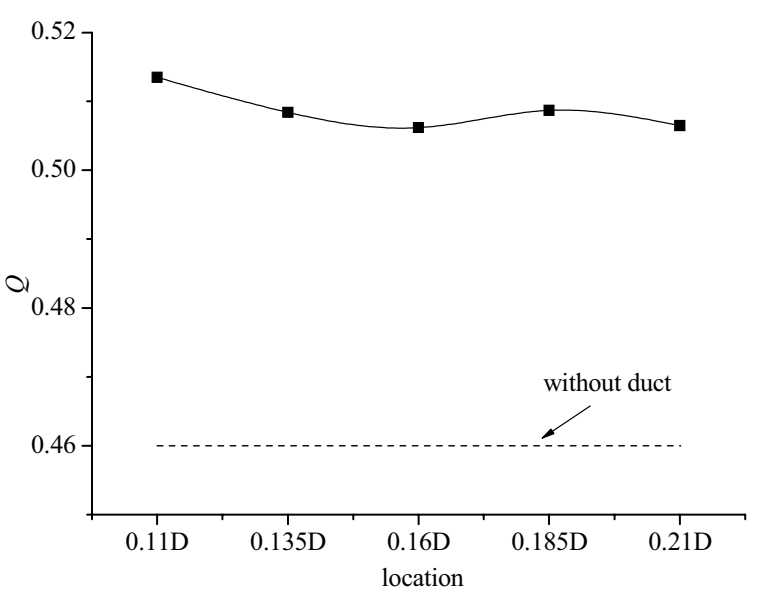

b

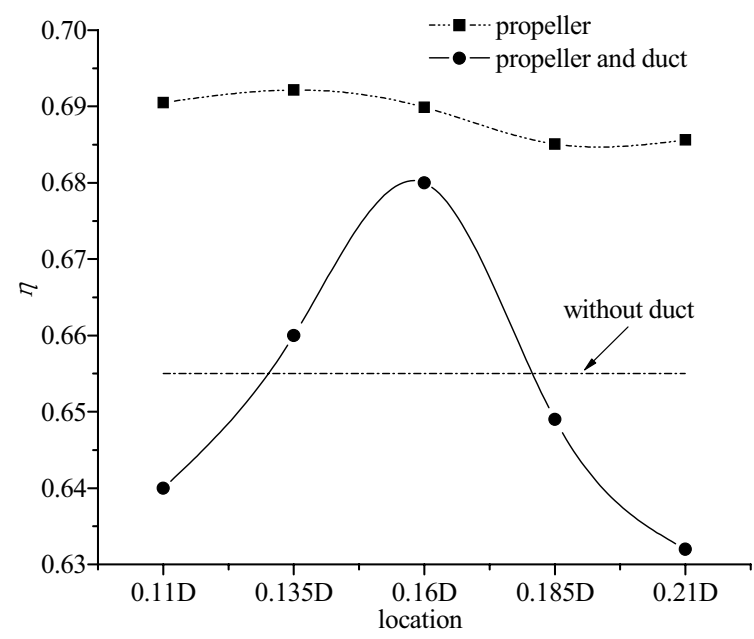

c

Fig. 8 Propulsion performance for different duct locations: a thrust, $\mathbf{b}$ torque, $\mathbf{c}$ propulsion efficiency

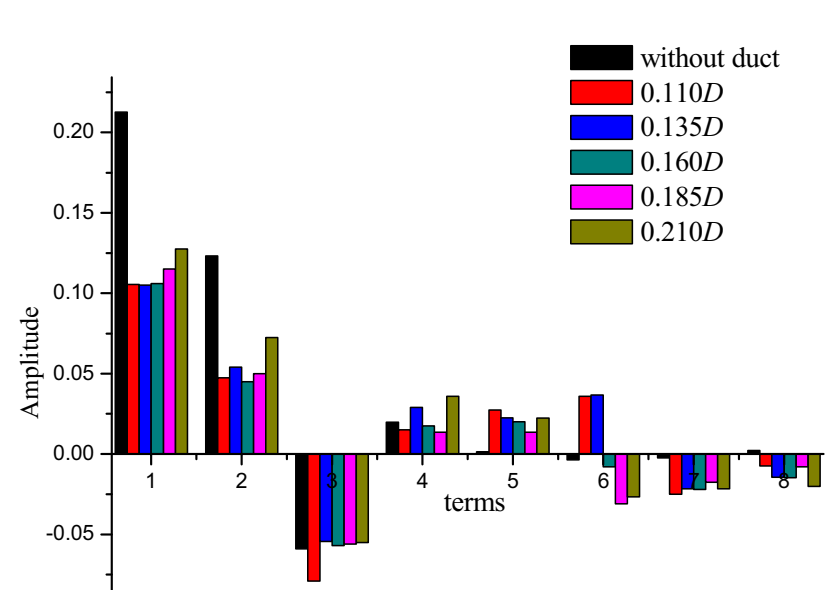

Fig. 9 Axial wake harmonic degree at $r / R=0.7$ on the propeller disc for various duct locations

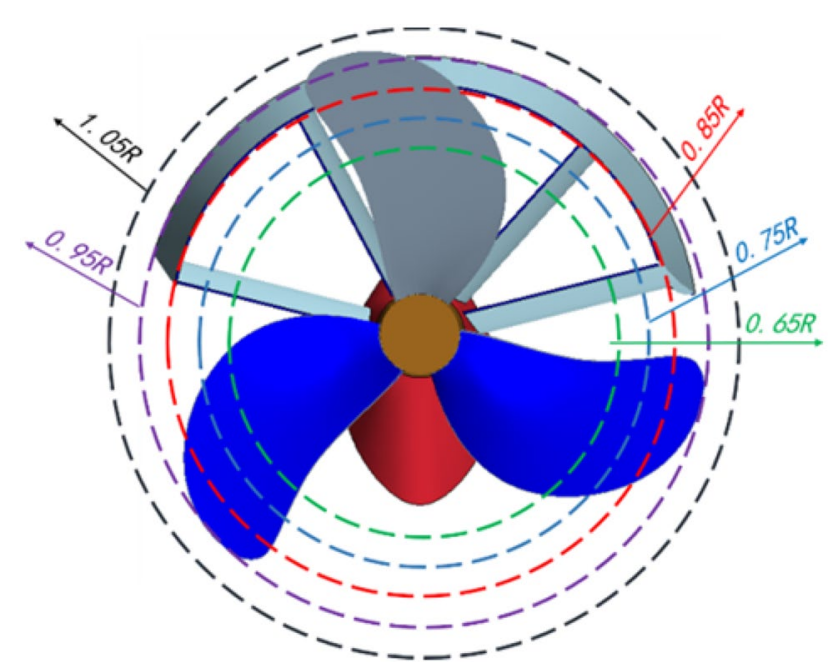

Fig. 10 Duct radius 


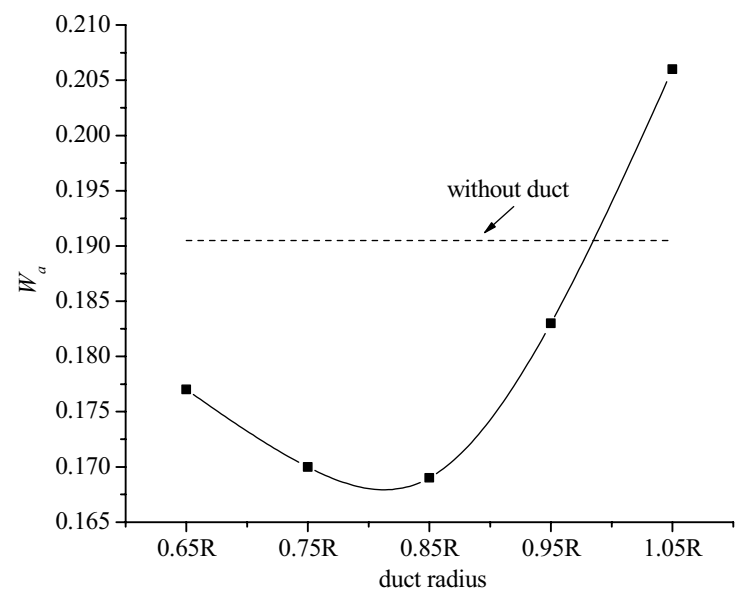

$\mathbf{a}$

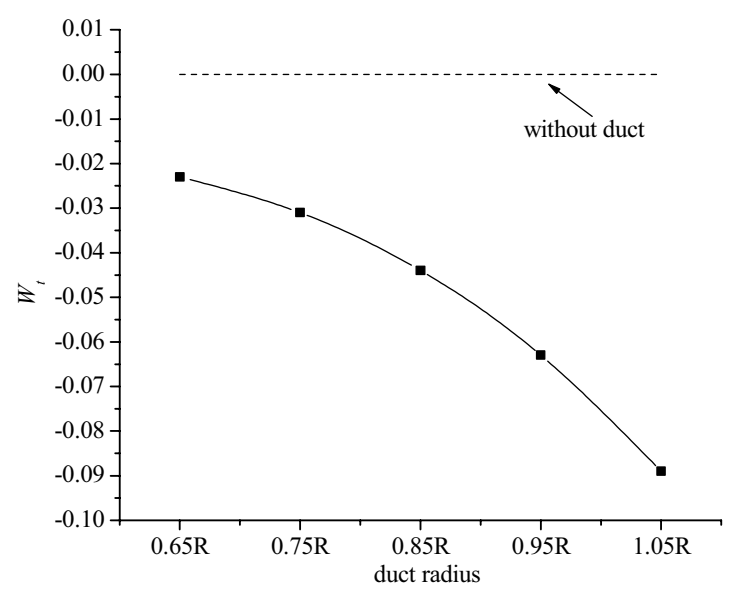

b

Fig. 11 Wake for different duct radius: a axial wake fraction and $\mathbf{b}$ tangential wake fraction

optimal when the duct location was $0.16 D$, which is very beneficial in the reduction of propeller noise and excited forces.

\subsection{Duct radius of the trailing edge}

As shown in Fig. 10, the duct radius in this paper refers to the radius of the trailing edge of the duct. The angle of attack of the inner fins was taken as $10^{\circ}$ and the duct location of $0.16 D$. The duct locations were $0.65 R, 0.75 R, 0.85 R, 0.95 R$, and $1.05 R$, respectively.

The axial mean nominal wake fraction and tangential wake fraction on the propeller disc with respect to the duct radius are plotted in Fig. 11. Figure 12 shows the hydrodynamic performance of the single propeller and the propulsion system consisting of the propeller and duct according to the duct radius.

Figure 11a shows that the axial mean wake fraction on the propeller disc varied greatly when the duct radius was different. The axial mean wake fraction decreased rapidly when the duct radius was less than $0.85 R$ while increasing rapidly when the duct radius was greater than $0.85 R$. When the duct radius was greater than the radius of the propeller, the wake fraction was greater than that without the duct. This shows that the outer duct plays a dominant role in the rectification and acceleration of the wake field of the ship when the duct radius is small. However, when the duct radius increases, the effect of the rectification and acceleration of the wake field of the outer duct decreases until it disappears. Meanwhile, the inner fins play a dominant role in blocking the the axial inflow of the propeller. As can be seen from Fig. 11b, the mean tangential wake fraction increased along with the increase of the duct radius, which is because the inner fins can affect larger regions of the inflow of the propeller as their length increases.

Figure 12 shows the hydrodynamic performance of the single propeller and the propulsion system consisting of the propeller and duct according to the duct radius. As shown in Fig. 12, the thrust and torque of the propeller increased with the increasing duct radius, while the efficiency increased first and then decreased reaching the maximum at the duct radius of $0.85 R$. As shown in Fig. 12a, the total thrust of the propeller and the duct was greater than that of the single propeller when the duct radius was smaller than $0.75 R$ and less than that of the single propeller when the duct radius was larger than $0.75 R$. This suggests that additional thrust was produced on the fan-shaped Mewis duct when the duct radius was small. In fact, additional thrust was produced on the outer duct, and additional resistance was caused by the inner fins. When the duct radius was small, the thrust was greater than the resistance; thus, additional thrust was generated on the fan-shaped Mewis duct. With the increase of the duct radius, the resistance increased more rapidly than the thrust because of the increase of the inner fins length, which results in the additional resistance on the fan-shaped Mewis duct. Figure 12c shows that the efficiency of the propeller and duct increased with the increasing duct radius, and then decreased rapidly when the duct radius was greater than $0.75 R$. When the duct radius was greater than $0.85 \mathrm{R}$, the efficiency was lower than that of propeller without the duct, which indicates that the duct radius should be less than $0.85 R$.

Figure 13 shows numerical results of the axial wake harmonic degree at the radius $0.75 R$ of the propeller disc according to the duct radius. The first eight terms of the amplitude are listed. As can be seen from Fig. 13, with the 


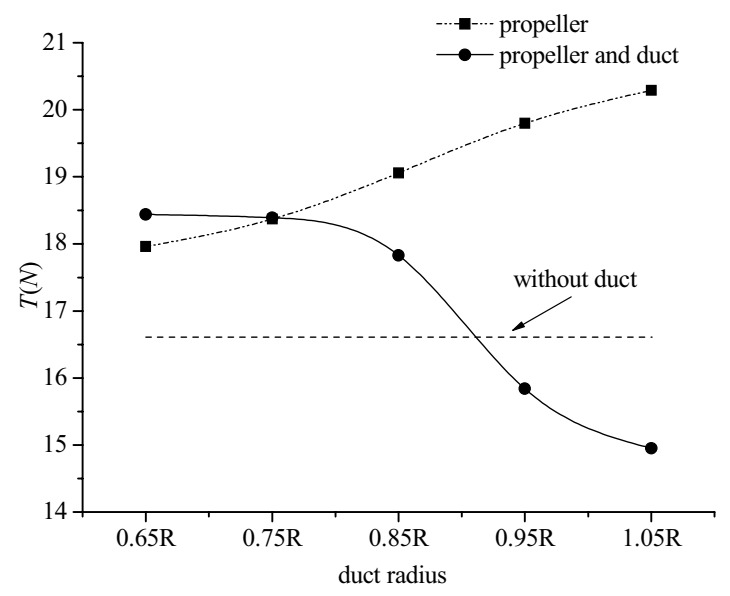

$\mathbf{a}$

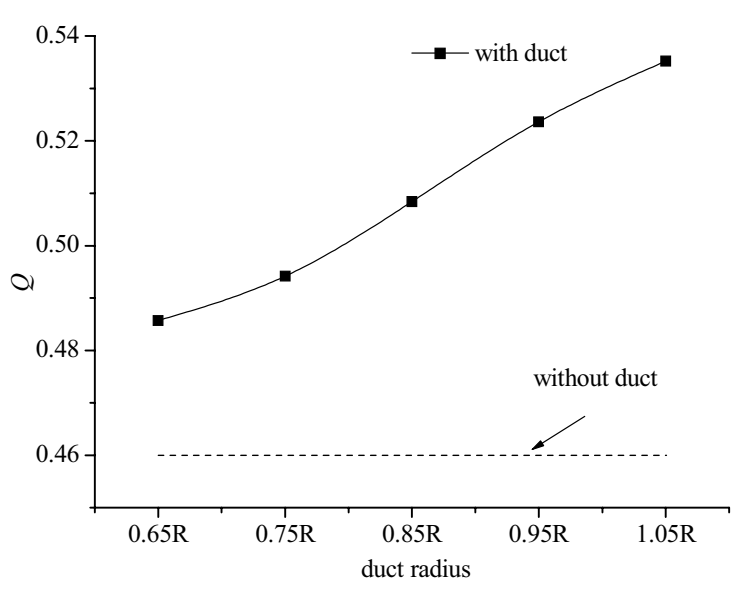

b

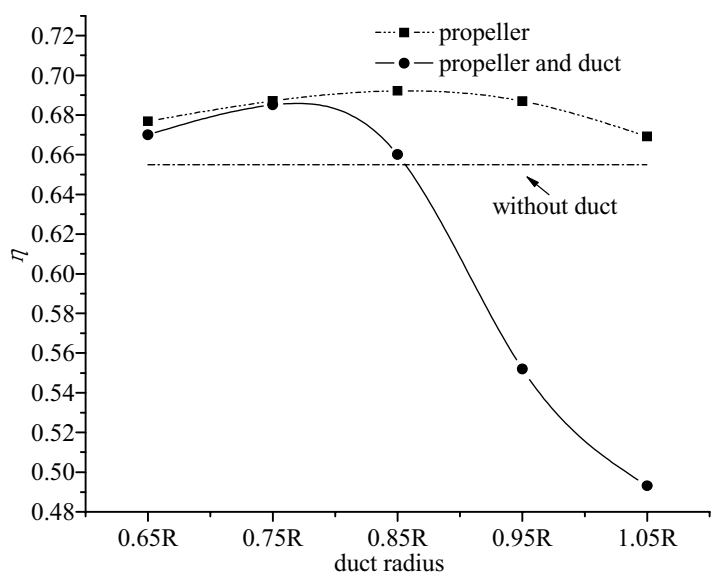

c

Fig. 12 Propulsion performance for different duct radius: a thrust, $\mathbf{b}$ torque, and $\mathbf{c}$ propulsion efficiency

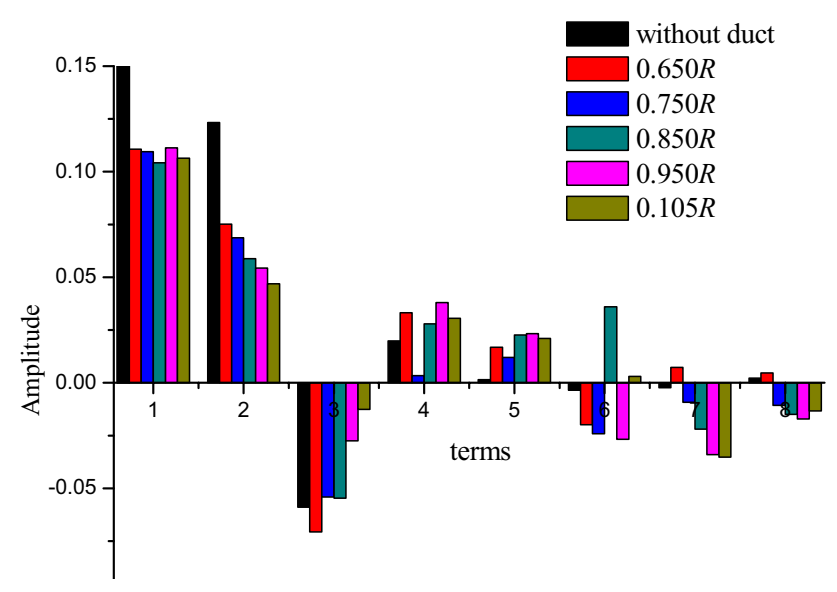

Fig. 13 Axial wake harmonic degree at $r / R=0.7$ on the propeller disc for different duct radius

increase of the duct radius, the first term of the axial wake amplitude varied slightly, while the second and third terms of the axial wake amplitudes decreased gradually.

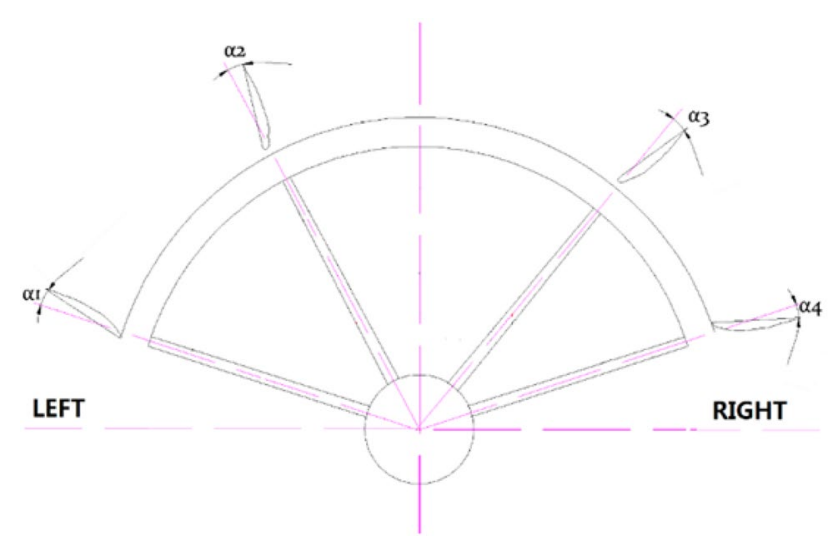

Fig. 14 Angle of attack of the inner fins of the duct

\subsection{Angle of attack of the inner fins of the duct}

The duct radius was taken as $0.75 R$ and the duct location of $0.16 \mathrm{D}$; the angle of attack of the inner fins was $0^{\circ}, 5^{\circ}, 10^{\circ}$, 


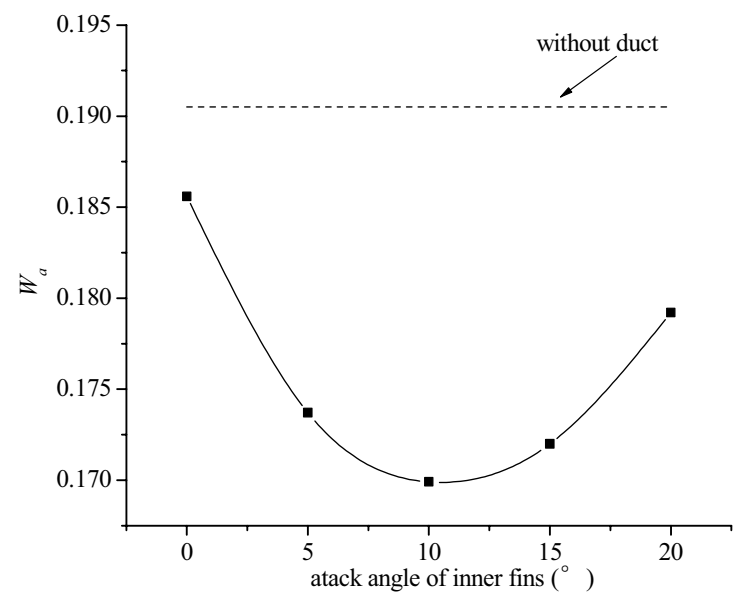

a

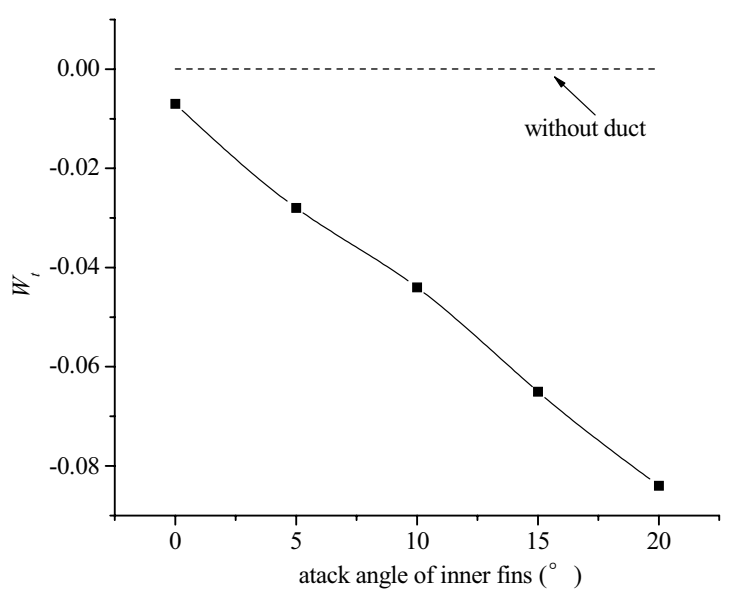

b

Fig. 15 Wake for different angle of attack of the inner fins of the duct: $\mathbf{a}$ axial wake fraction and $\mathbf{b}$ tangential wake fraction

$15^{\circ}$, and $20^{\circ}$, respectively, as shown in Fig. 14 .

Figure 15a shows that the axial mean wake fraction on the propeller disc varied greatly when the angle of attack of inner fins was different. The axial mean wake fraction decreased rapidly when the angle of attack of the inner fins was less than $10^{\circ}$ while increasing rapidly when the angle of attack of the inner fins was greater than $10^{\circ}$. This shows that the outer duct played a dominant role in the rectification and acceleration of the wake field of the ship when the angle of attack was small. However, when the angle of attack of the inner fins increased, the axial component of the wake flow decreased rapidly with the water flowing through the inner fins, thus reducing the axial inflow velocity of the propeller. It can be seen from Fig. 15b that the mean tangential wake fraction increased along with the increase of the angle of attack of the inner fins, which is because the greater the angle of attack of the inner fins is, the greater the tangential component of the wake flow will be.

The hydrodynamic performance of the single propeller and the propulsion system consisting of the propeller and duct according to the angle of attack of the inner fins is plotted in Fig. 16. From Fig. 16, the following conclusions are drawn. The angle of attack of the inner fins had great influence on the hydrodynamic performance of the propeller. The thrust, torque, and efficiency of the propeller increased with the increase of the angle of attack of the inner fins. It can be seen from Fig. 15 that when the angle of attack of the inner fins was less than $10^{\circ}$, the axial mean wake fraction decreased, while the tangential mean wake fraction increased; thus, the propeller efficiency increases gradually. When the angle of attack of the inner fins was greater than $10^{\circ}$, the mean axial wake fraction and the mean tangential wake fraction were all growing, and the effect of tangential flow apparently played a leading role. Thus, the propeller efficiency still increased with the increase of the angle of attack of the inner fins. As seen from Fig. 16a, the total thrust of the propeller and duct was less than that of the single propeller. The total thrust of the propeller and duct first increased and then decreased with the increase of the angle of attack of the inner fins, and reached the maximum when the angle of attack of the inner fins was $10^{\circ}$. This is because when the angle of attack of inner fins was greater than $10^{\circ}$, larger tangential wake flow not only made the relative rotation speed of the propeller higher, improving the propeller efficiency, but also resulted in greater additional resistance. This offset the gains of the improvement of the propeller efficiency. It can be seen from Fig. 16c that the efficiency of the propulsion system consisting of the propeller and the fan-shaped Mewis duct reached the highest at the $10^{\circ}$ angle of attack for the inner fins. Moreover, only when the blade angle of attack was approximately between $15^{\circ}$ and $12^{\circ}$ was the energy-saving effect achieved.

Figure 17 shows the numerical results of the axial wake harmonic degree at the radius $0.75 R$ of the propeller disc according to the angle of attack of the inner fins. The first eight terms of the amplitude are listed. From Fig. 17, the following conclusions were drawn. When the angle of attack of the inner fins was small, the axial wake with the duct was more uniform than that without duct, and the first two terms of the axial wake amplitudes decreased remarkably. When the angle of attack of the inner fins was greater than $15^{\circ}$, the first term of the axial wake amplitude with the duct increased approaching that of without the duct, which shows that too large of an angle of attack of the inner fins was unfavorable to the uniformity of the axial wake. After installing the duct, the axial wake flow was more uniform than that without the duct, and the first two terms of its amplitudes decreased significantly. It can be understood that when the angle of attack 


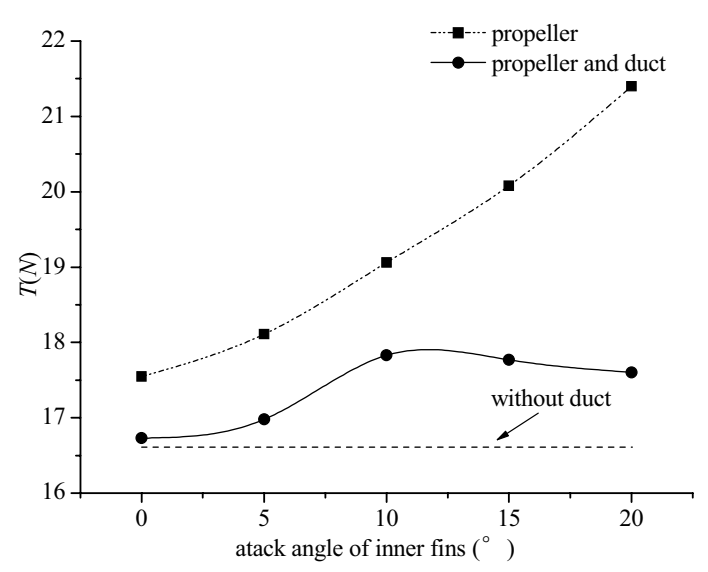

a

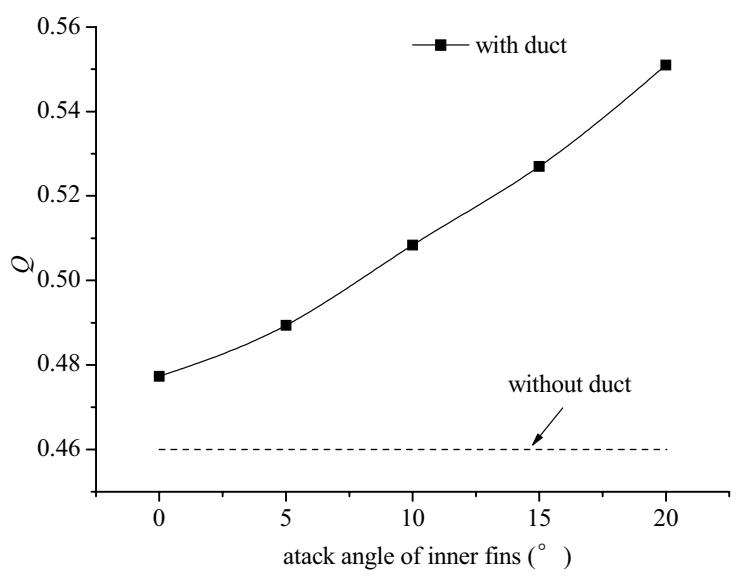

b

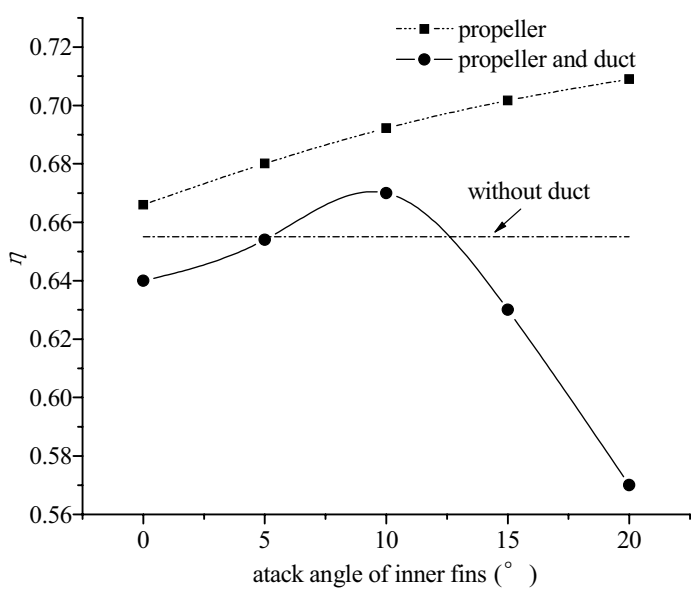

c

Fig. 16 Propulsion performance for different angle of attack of the inner fins of the duct: a thrust, $\mathbf{b}$ torque, and $\mathbf{c}$ propulsion efficiency

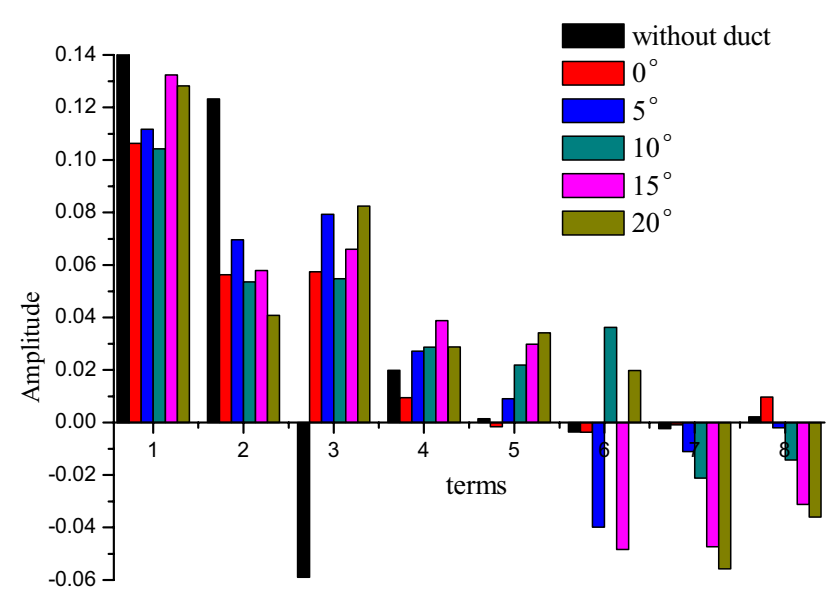

Fig. 17 Axial wake harmonic degree at $r / R=0.7$ on propeller disc according to angle of attack of inner fins of the duct

of the inner fins was $10^{\circ}$, the axial wake flow at the propeller disc was most uniform.

\section{Conclusions}

The effect of a fan-shaped Mewis duct on propeller performance was numerically investigated by considering a wide range of locations from $0.11 D$ to $0.21 D$, radius from $0.65 R$ to $1.05 R$, and angle of attack of the inner fins from $0^{\circ}$ to $10^{\circ}$ of the fan-shaped Mewis duct for a small bulk cargo ship with a three-blade propeller. The profile of the outer duct and inner fins were all designed using NACA0015. The angle of attack of the outer duct was $15^{\circ}$ with a chord length of $0.28 D$, while the chord length of the inner fins was $0.18 D$. The design speed of the ship model was $1.2731 \mathrm{~m} / \mathrm{s}$. The mean wake fractions, propulsion characteristics and wake harmonic degree were analyzed carefully. The main conclusions of the present study are summarized as follows.

The existence of the fan-shaped Mewis duct reduced the axial wake and increased the tangential wake on the propeller plane. With the decrease of the axial flow, the inflow speed of the propeller was increased, and with the increase 
of the tangential wake, the relative rotation speed of the propeller was increased. This resulted in an increased propeller thrust. However, the real rotation speed of the propeller did not change; thus, it improved the efficiency of the propeller.

As the installation position became further away from the propeller, the axial mean wake fraction varied in a wave pattern, while the tangential mean wake fraction decreased gradually. When not considering the additional resistance produced by the fan-shaped Mewis duct, with the increasing distance between the fan-shaped Mewis duct and the propeller, the thrust and torque of the propeller showed the same increasing patterns with that of the mean axial wake fraction. However, the efficiency varies in the opposite way. It was observed that the tangential flow was so small that the axial wake is a more important variable. In addition, the hydrodynamic forces and efficiency of the propeller itself were greatly improved because of the installation of the fan-shaped Mewis duct. All the coefficients of the propeller with the duct installed were larger than that of the propeller without the duct. However, if regarding the propeller and duct as a propulsion system, the thrust and efficiency of this system were significantly smaller than that of propeller itself. In addition, only when the fan-shaped Mewis duct was mounted approximately between $0.13 D$ and $0.18 D$ of the distance from the propeller disc, the efficiency of the propulsion system was higher than that in the case without installing the fan-shaped Mewis duct. The maximum efficiency was achieved near $0.16 D$.

With the increase of the radius of the fan-shaped Mewis duct, the axial mean wake fraction first decreased and then increased, while the tangential mean wake fraction increased quickly. Both thrust and torque of the propeller increased, while the radius of the fan-shaped Mewis duct increased. The efficiency of the propeller increased first and then decreased. The propeller performance was affected by the axial wake and the tangential wake simultaneously, but the tangential wake was a more important variable. The maximum efficiency of the propulsion system consisting of the propeller and the fan-shaped Mewis duct was achieved when the duct radius was equal to $0.75 R$. Moreover, only when the duct radius was less than $0.85 R$ did the efficiency of the propulsion system reach higher values than that of the propeller without the fan-shaped Mewis duct.

With the increase of the angle of attack of the inner fins of the fan-shaped Mewis duct, the axial mean wake fraction first decreased and then increased, while the tangential mean wake fraction increased quickly. The thrust, torque, and efficiency of the propeller all increased, while the angle of attack of the inner fins of the fan-shaped Mewis duct increased. Thus, the tangential wake was more important than the axial wake. The efficiency of the propulsion system consisting of the propeller and the fan-shaped Mewis duct increased gradually along with the increase of the angle of attack of the inner fins, and reached the maximum near $10^{\circ}$. When the angle of attack of the inner fins was greater than $10^{\circ}$, the efficiency dropped rapidly. When the angle of attack of inner fins was approximately between $5^{\circ}$ and $12^{\circ}$, the efficiency of the propulsion system was higher than that of the propeller without the fan-shaped Mewis duct. This is because the tangential wake increased along with the increase of the angle of attack of the inner fins, which was equivalent to increasing the relative revolution speed of the propeller thus increasing the propeller thrust. However, when the angle of attack of the inner fins was greater than $10^{\circ}$, the resistance of the fan-shaped Mewis duct increased faster than the propeller thrust.

The axial wake harmonic degree on the propeller disc had been significantly improved with the installation of the fan-shaped Mewis duct, which means that the propeller noise and excited forces were effectively controlled. There were also optimal parameters of the fan-shaped Mewis duct corresponding to the best axial wake harmonic degree, but the parameters were sometimes inconsistent with that corresponding to the best energy efficiency.

The research in this study showed that the thrust of the propeller was increased with the installation of the fanshaped Mewis duct, but the ship's total resistance was also increased. Therefore, to achieve energy savings, it is necessary to optimize the parameters of the fan-shaped Mewis duct to ensure that the gains from the increase of the propeller thrust is greater than the adverse effects caused by the increase in resistance.

Consequently, it is believed that the main findings given in this study are helpful in understanding the relationship between that of the propulsion performance of the propeller and the parameters of the Mewis duct, which is very beneficial to the design of these parameters. In the future, more parameters such as the angle of attack and the profile of the outer duct and inner fins should be considered.

Acknowledgements The hull and duct data are provided by Shanghai Merchant Ship Design and Research Institute, and the present work is supported by the High Technology Marine Scientific Research Project of Ministry of Industry and Information Technology of China (Grant No. [2012]534) and the National Natural Science Foundation of China (Grant Nos. 51379040, 51679052). We would like to express our deep appreciation to Shanghai Merchant Ship Design and Research Institute and Ministry of Industry and Information Technology of China.

Open Access This article is distributed under the terms of the Creative Commons Attribution 4.0 International License (http://creativeco mmons.org/licenses/by/4.0/), which permits unrestricted use, distribution, and reproduction in any medium, provided you give appropriate credit to the original author(s) and the source, provide a link to the Creative Commons license, and indicate if changes were made. 


\section{References}

1. Carlton J (2012) Marine Propellers and Propulsion (Third Edition). Butterworth-Heinemann, Oxford, pp 319-328

2. Baek DG, Yoon HS, Jung JH, Kim KS, Paik BG (2015) Effects of the advance ratio on the evolution of a propeller wake. Comput Fluids 118:32-43

3. Ma C, Qian ZF, Zhang X, Du D (2005) Numeric computation and simulation on the hydrodynamic performance of the propellerrudder-rudder bubble combination. Chuan Bo Li Xue/J Ship Mech 9(5):38-45

4. Çelik F, Güner M (2007) Energy saving device of stator for marine propellers. Ocean Eng 34(5-6):850-855

5. Hsin CY, Lin BH, Lin CC (2009) The optimum design of a propeller energy-saving device by computational fluid dynamics. Computational fluid dynamics 2008, pp 655-660

6. Ahn K, Choi GH, Son DI, Rhee KP (2012) Hydrodynamic characteristics of X-Twisted rudder for large container carriers. Int $\mathrm{J}$ Naval Archit Ocean Eng 4(3):322-334

7. Kawamura T, Ouchi K, Nojiri T (2012) Model and full scale CFD analysis of propeller boss cap fins (PBCF). J Mar Sci Technol 17(4):469-480

8. Schuiling B (2013) The design and numerical demonstration of a new energy saving device. In: 16th Numerical towing tank symposium

9. Kim JH, Choi JE, Choi BJ, Chung SH (2014) Twisted rudder for reducing fuel-oil consumption. Int J Naval Archit Ocean Eng 6(3):715-722

10. Lee KJ, Bae JH, Kim HT, Hoshino T (2014) A performance study on the energy recovering turbine behind a marine propeller. Ocean Eng 91:152-158

11. Wang C, He M, Wang GL, Guo CY (2014) Design and performance analysis of twisted rudder based on the maximum reduction of rudder resistance. Chuan Bo Li Xue/J Ship Mech 18(3):238-247

12. Kim JH, Choi JE, Choi BJ, Chung SH, Seo HW (2015) Development of Energy-Saving devices for a full Slow-Speed ship through improving propulsion performance. Int J Naval Archit Ocean Eng 7(2):390-398

13. Park S, Oh G, Hyung Rhee S, Koo BY, Lee H (2015) Full scale wake prediction of an energy saving device by using computational fluid dynamics. Ocean Eng 101:254-263

14. Dang J, Chen H (2016) Energy saving by using asymmetric aftbodies for merchant ships-design methodology, numerical simulation and validation. J Hydrodyn 28(6):1022-1028

15. Fu H, Ma N, Yang C, Jiang J (2016) Numerical simulation of energy saving effects of pre-swirl stators and mechanism analysis. In: Proceedings of the international offshore and polar engineering conference, pp 869-874

16. Ni B, Huang G, Li P, Yan Z, Zhao L (2016) Design and application of high efficiency propeller integrated with HVAF for retrofit on a 20000DWT bulk carrier. Ship Build China 57(4):34-43

17. Sun Y, Su YM, Hu HZ (2016) Research on influence of rudderbulb-fin parameters on hydrodynamic performance of twisted rudder. Chuan Bo Li Xue/J Ship Mech 20(9):1071-1082

18. Mizzi K, Demirel YK, Banks C, Turan O, Kaklis P, Atlar M (2017) Design optimisation of propeller boss cap Fins for enhanced propeller performance. Appl Ocean Res 62:210-222

19. Schneekluth $\mathrm{H}$ (1986) Wake equalising duct, state of development. Lips Propeller Symposium, 6th Drunen, Netherlands
20. Dayuan D (1991) Energy saving device-a research for production of rudder-ball and wake equalizing ducts. In: Propeller/shafting '91 symposium Virginia Beach, VA

21. Friesch J, Johannsen C (1994) Propulsion optimization tests at high Reynolds numbers. SNAME Trans 102:1-21

22. Korkut E (2006) A case study for the effect of a flow improvement device (a partial wake equalizing duct) on ship powering characteristics. Ocean Eng 33(2):205-218

23. Çelik F (2007) A numerical study for effectiveness of a wake equalizing duct. Ocean Eng 34(16):2138-2145

24. Mewis F (2008) Development of a novel power-saving device for full-form vessels. HANSA 145:46-50

25. Mewis F (2009) A novel power-saving device for full-form vessels. In: SMP'09

26. Mewis F (2011) Mewis duct ${ }^{\circledR}$ —new developments, solutions and conclusions. In: Proceedings of 2nd international symposium on marine propulsors, SMP'11.

27. Hans-Jürgen Heinke KH-R (2011) Investigation of scale effects on ships with a wake equalizing duct or with vortex generator fins. In: Second international symposium on marine propulsors Smp'11, Hamburg, Germany

28. Feizi Chekab MA, Ghadimi P, Reza Djeddi S, Soroushan M (2013) Investigation of different methods of noise reduction for submerged marine propellers and their classification. Am J Mech Eng 1(2):34-42

29. Go JS, Yoon HS, Jung JH (2017) Effects of a duct before a propeller on propulsion performance. Ocean Eng 136:54-66

30. Dang J, Chen H, Dong G, Van Der Ploeg A, Hallmann R, Mauro F (2011) An exploratory study on the working principles of energy saving devices (ESDs). In: Proceedings of international symposium on green ship technology, Greenship' 2011

31. Dang J, Dong G, Chen H (2012) An exploratory study on the working principles of energy saving devices (ESDs)—PIV, CFD investigations and esd design guidelines. In: Proceedings of the international conference on offshore mechanics and arctic engineering-OMAE, pp 25-34

32. Guiard T, Leonard S (2013) The Becker Mewis duct—challenges in full-scale design and new developments for fast ships. In: 3rd international symposium on marine propulsors, Launceston

33. Jil-Pyo O (2005) Power savings by wake equalizing ducts? Ship Technol Res 52(1):34-51

34. Martinas G (2015) Cavitation of a propeller and influence of a wake equalizing duct. Int J Mar Navig Saf Sea Transp 9(2):235-241

35. Yuhai K, Cai R, Wang J, Zhang Y (2013) Numerical study of energy-saving mechanism of duct on a VLCC with real-geometry propeller. In: The third international symposium on marine propulsors (SMP'13), Launceston, Tasmania

36. The specialist committee on CFD in Marine Hydrodynamics. Final report and Recommendations to the 27th ITTC. The 27th ITTC, Copenhagen, Denmark, pp 530-533

37. CD-Adapco (2016) User guide STAR-CCM + version 11.04

38. Choi JE, Min KS, Kim JH, Lee SB, Seo HW (2010) Resistance and propulsion characteristics of various commercial ships based on CFD results. Ocean Eng 37(7):549-566

39. Lindgren H, Aucher M, Bowen BS, Gross A, Minssas KJ, Muntjewerf JJ, Tamura K, Wermter R (1978) Report of the performance committee. In: Proceedings of the 15th international towing tank conference. 15th ITTC

40. Choi JE, Kim JH, Lee HG, Choi BJ, Lee DH (2009) Computational predictions of ship-speed performance. J Mar Sci Technol 14(3):322-333 